\title{
Computer-Based EFL Teaching Mode Research
}

\author{
Wenlian, Zhan ${ }^{1, \mathrm{a}}$, Zhulin, Shen ${ }^{1, \mathrm{a}}$ \\ ${ }^{1}$ School of Foreign Languages,Hunan International Economics University \\ Changsha, China \\ ae-mail: 513869962@qq.com
}

\begin{abstract}
As the core part of the College English Teaching Reform, computer-based classroom English teaching mode has not yet been effectively implemented due to the failure in computer application. To effectively carry out the teaching mode innovation we should integrate modern education Technology _ computer into the curriculum, making it one organic part of the curriculum and one of the key factors of the teaching system.
\end{abstract}

Keywords- teaching mode, computer-based, integration, network.

\section{INTRODUCTION}

Computer-assisted classroom English teaching mode is the core of college English teaching reform. However, how to put it into practice properly is the key to reform. Effectively explored in this article from the college English teaching reform of teaching new mode of departure, analyzes the status quo of foreign language teaching, and set forth on the basis of the relationship between the computer and foreign language teaching, the advantage thus proposed the integration of computer and foreign language courses.

The teaching model is actually the core of the college English teaching reform, new public English teaching mode should be a combination of classroom teaching English teaching software running on the campus online teaching mode as the main development direction. Thus, the curriculum proposed a new foreign language teaching mode, the computer-based and classroom English teaching mode "(hereinafter referred to as the" new model ") (see Figure 1).

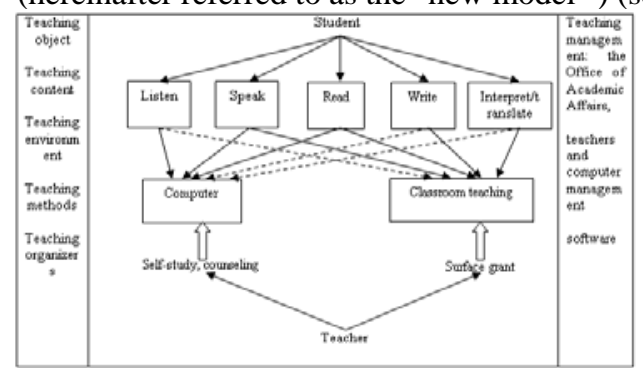

Figure 1. Computer-based classroom English teaching mode

According to the new model, the English and teaching activities of reading, writing and translation by computer, can also be carried out by classroom teachers; shown in Figure 1, the solid line arrows indicate some kind of teaching environment dashed arrows, supplemented in some teaching and learning environment. That is to say, "Listen" training in a computer network environment, complemented by classroom teaching; "say" and "read" the training necessary to be in a computer network environment, as well as classroom teaching; "write" and "translated" training supplemented by classroom teaching, teaching computer network environment.

\section{TO BREAK THE LIMITATIONS OF THE CLASSROOM TEXTBOOK}

Computer aided instruction is still the basis of classroom and textbooks, that is the only source of textbooks students knowledge, as shown in Figure 2:

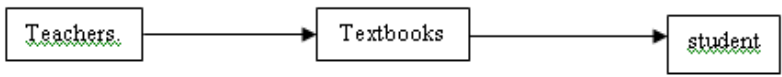

Figure 2. Textbook-based teaching

The relationship among teachers, textbooks, student teachers dominate the classroom, and analysis and interpretation of a medium to transfer knowledge to students, textbooks just teachers and students to communicate through the use of textbooks, students learn through the analysis and interpretation of the teachers on textbooks (accepted) knowledge. The essential characteristic of this model is a teacher-led instruction, students are in a passive position, became the object of knowledge "indoctrination", even though the teachers to use the computer as a teaching aid, shown in Figure 3:

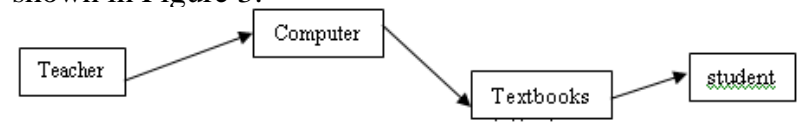

Figure 3. Traditional computer-aided teaching mode

Teachers just teach textbook knowledge through a computer presentation or explain to the students, the computer is just to enhance teaching effectiveness and means, but the classroom + textbooks traditional form of teaching and textbooks is the situation of the students only source of knowledge not been broken. However, computer networks, and curriculum integration can change this situation, because the teaching framework of a fundamental change occurred, as shown in Figure 4:

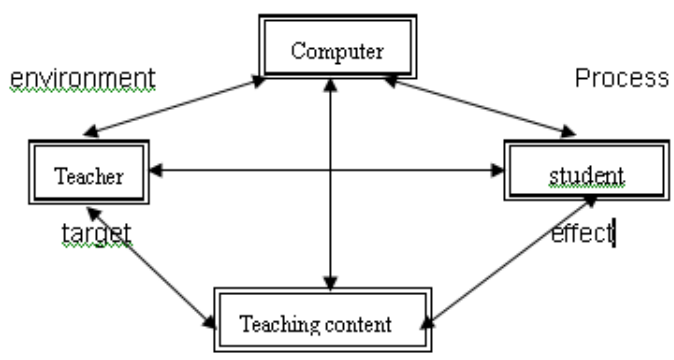

Figure 4. Computer and foreign language curriculum integration framework 
Teaching elements, the relationship between the teachers, students, computer science, and teaching content is not a one-way, but a two-way linkages, interaction, interdependence, mutual conversion. This computer curriculum integration framework, teachers' role has undergone a fundamental change, they no longer the center of the classroom instruction, students from passive recipients of knowledge into active constructors of knowledge, students also will be a single source of knowledge textbook paper media to expand for many medium, as shown in Figure 5:

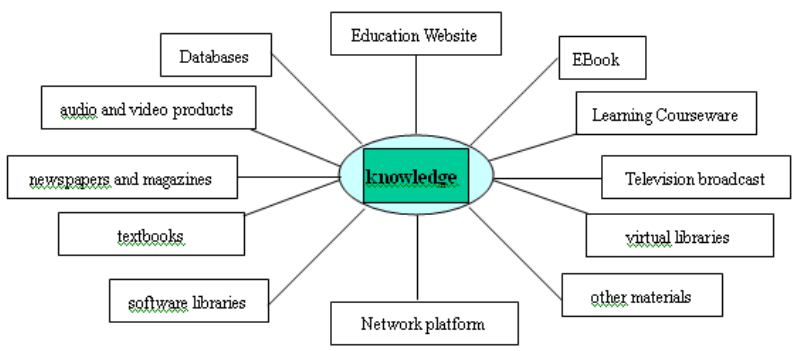

Figure 5. Sources of knowledge

It can be seen in the whole learning process, students may contact the knowledge far beyond the scope of textbooks, they can have many ways to engage in meaningful initiative to build the knowledge.

\section{CREATE AN IDEAL ENVIRONMENT AND WAY OF TEACHING AND LEARNING}

Computer networks and foreign language courses integrate environment and the way that is conducive to the creation of the ideal teaching and learning. The creation of this ideal environment thanks to the rapid development of computer network technology, to create the conditions for student-centered learning.

The ideal environment for foreign language teaching, from the perspective of the foreign language communication theory, is a student-centered learning environment. Studentcentered learning environment based on the following three basic assumptions (Morrison \& Lowther, 2005): First of all, a student-centered learning emphasis on the understanding of the human world, rather than a simple imitation (mechanical memory). Understanding that learners renovation and conversion of the results (Gardner, 1991), the understanding of the human world require students to take the initiative to processing and handling information. Second, studentcentered learning emphasizes that students should strive to reduce the difference between the known areas and unknown areas, this difference is caused by the students' cognitive dissonance is to create a new understanding to resolve differences motivator (Brooks \& Brooks, 1993). Third, the emphasis on collaborative learning and personal understanding of the evaluation to student-centered learning, to the knowledge of the individual to be refined. Students with the other students to test their understanding, and look at the level of understanding of others. This provides a good knowledge of innovative building conditions and environment for students through individual evaluation and cognitive understanding. Based on three assumptions, the ideal student-centered teaching and learning environment should contain situational learning, co-operative learning and open learning three elements:

1)Learning situationalization. The traditional textbook learning and teaching is separated from the scenario. The effectiveness and appropriateness of this approach has been questioned educators (Brown, Collins \& Duguid, 1989). For example, a common foreign language textbooks written: text theme content on banks, such as account opening, savings, exchange, close family, and so on, and each and every aspect may be some exemplary dialogue, teachers on the dialogue, students The imitate drill. This teaching is more abstract, not to provide students with a meaningful scene. However, computer networks and the integration of foreign language courses, like this content on banking topics we can on a computer network to create an immersive banking environment, students can enter the virtual reality environment to learn about accounts, savings, exchange, real close family and other aspects of the language, and truly meet the needs of the students in the training of listening and speaking ability.

2)The co-operative learning. Student-centered teaching and learning environment, teachers and students and among students, more than ever the need for cooperation. The integrated teaching structure as teachers can no longer accept the concept of the isolation policy makers. Teachers and students should become one of the team, more adaptive and effective exchange and discussion with others. Teachers should not only become a model of cooperation in their work is also required to promote collaboration between students in the teaching process, training them to cooperate in the ability to learn a foreign language communicative. The co-operative learning, teachers should learn to group learning integration into their teaching activities, but also understand that not all group learning means that the co-operative learning. Therefore, the distinction between the promotion of cooperation, learning and teaching social skills development characteristics of the traditional group characteristics (Morrison \& Lowther, 2005), it is very important:

TABLE I. THE JOINT WORKING GROUP AND THE TRADITIONAL GROUP COMPARISON

\begin{tabular}{|c|c|}
\hline $\begin{array}{c}\text { The J oint Working } \\
\text { Group }\end{array}$ & The traditional group \\
\hline Heterogeneous & Homogeneous \\
\hline $\begin{array}{l}\text { Emphasis on social } \\
\text { skills } \\
\text { Stressed task and } \\
\text { group maintenance }\end{array}$ & $\begin{array}{c}\text { Setting social skills } \\
\text { Only emphasized the } \\
\text { task }\end{array}$ \\
\hline $\begin{array}{l}\text { Teachers observe and } \\
\text { promote } \\
\text { Shared leadership and } \\
\text { responsibility }\end{array}$ & $\begin{array}{l}\text { Teachers ignore the } \\
\text { team function } \\
\text { Single leadership and } \\
\text { personal responsibility }\end{array}$ \\
\hline Mutual aid & No mutual aid \\
\hline
\end{tabular}

This shows that the cooperative group learning and traditional group learning, which requires very different in 
essence should have a fundamental change in the traditional role of teachers and students. Computer network and curriculum integration, making it an organic part of the course, be possible to shift to this role.

3)Open learning. Such a learning environment usually require students through contact, transformation, conversion of new information to solve the problem, and to reach a new understanding. Open learning environment is mainly based on two methods: inquiry-based learning (inquiry learning) and task-based learning (task-based learning).

Inquiry-based learning requires students found that the relationship between the new concept (classification), and the original concept (principle) (Brunner, 1960), by searching for relevant information, and encourage students to ask questions and find answers. Many experts (Greeno, Collins \& Resnick, 1996; Edelson, Gordin \& Pea, 1999) show that the inquiry-based learning real project and a realistic scenario, can effectively promote learning and knowledge. Barrows (1985) description of inquiry-based learning to the students first problem, and then they began to Research. Students must be independent or to reflect together on what they understand, and what they need to learn to solve problems. Students to establish a method to solve the problem by determining the knowledge they need, rather than textbooks presented traditional theme-based knowledge structure. A variety of tasks based on similar inquiry, taskbased learning is focused on providing learners with real scene to solve real problems in real society, to motivate students to learn new knowledge and information that can be used to complete the task. Inquiry learning task-based learning, have open learning characteristics, a focus on learners, allow students to decide for themselves what information is required and what method should be applied to solve the problem. The difference is that with traditional teaching: traditional teaching is selected by instruction and delivery of content, and open teaching selection, but let students needed. Open learning environments require teachers to adopt new methods, teachers as facilitators and mentors to help students understand the material, and to provide the necessary scaffold (scaffold).

Ideal teaching environment, students can put the computer network as a cognitive tool of inquiry (Student computer as the acquisition, analysis, processing and use of evaluation information tool), emotional incentive tool (the students to the computer as an incentive motives and character cultivation tools) and collaborative communication tools (student computer as a collaborative communication tools to promote the construction of meaning).

\section{FUNDAMENTAL CHANGES IN TEACHING STRUCTURE}

Computer networks and the integration of foreign language courses not only the creation of the ideal teaching environment, and more importantly, the system has undergone a fundamental change in the teaching structure. Equal emphasis on the teaching structure of the traditional teaching structural changes in order to "teach" the center of learning and teaching, teacher-led - the teaching structure of the student body, see Figure 6 below:

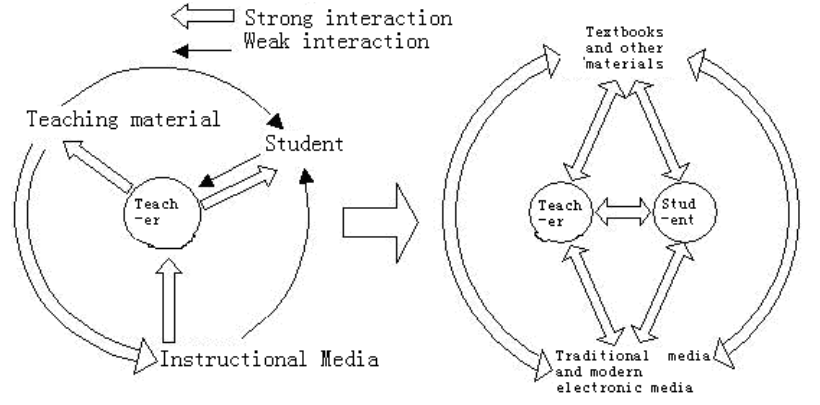

Figure 6. The left shows teacher-centered mode, the right studentdominated structure

1) The teachers led mainly active. This teaching structure, teachers have to change its role in the traditional sense, must have a new understanding of changing the structure of teaching. To this end, teachers first need to acquire new knowledge and experience how to make use of the advantages of the computer. As we all know, in our country for many years, our foreign language teaching in the traditional classroom. In this environment, always brief teachers, students listen or take notes. Classroom activities is nothing more than questions, points of practice, inspection testing. However, dominant - the main teaching structural requirements for the integration of the computer as an integral part of our foreign language teaching, teachers can learn from basically no experience. New teaching structure, teachers must allow students to construct or acquire new knowledge and use of computer networks, so they first have to experience the process of learning activities. This experience not only helps teachers to understand the advantages of the computer as well as students in learning activities may encounter problems and frustrations, but also help teachers targeted, reasonable structure design work. Second, teachers need to use their understanding of student learning knowledge and knowledge about the functions of the computer, to design, manage, maintain a student-centered, multi-dimensional learning environment. The teachers have a computer and curriculum integration of teaching experience, will be able to take advantage of the computer's advantage, combined with the learning characteristics of students to design and create the learning environment of the integrated curriculum. Teachers take on the role of the designer, every aspect of the course are given careful consideration and arrangements to support and promote meaningful learning of students. The same time, teachers also need to take on the role of the learning facilitator. In a traditional classroom, teachers provide students with the learning content, the main form of teachers say students listen. Learning facilitator role, however, is completely different with this, the teacher is no longer a simple explanation, but rather to provide to the students in a resource-rich learning environment to guide students into learning activities. In this learning environment, students cooperation learning or problem-solving. As a facilitator of learning, teachers in the learning process can keep abreast of progress in learning to inspire students to think about problems and make decisions by thinking. The role of teachers is also reflected in the demonstration or 
description of the steps to solve the problem for the learning activities of students. The role of teachers to ensure that students in the learning process the necessary learning stent or learning remedy, in order to successfully complete the learning task (Vygotsky, 1978). In addition, teachers need to act as a role of the manager, coordinate and improve the integration of the teaching process. Management lies not only in the design of classroom learning activities, need more real classroom management in a real teaching environment. Under normal circumstances, the design of the course, the teachers impossible to various details of the learning activities should have a comprehensive consideration, many of the problems are likely to appear suddenly, which requires teachers to make the appropriate coordination and processing, which is teachers manager role.

2) The student body is mainly reflected in the "studentcentered learning methods. Students as the image of "indoctrination" Dominated - teaching structure will be changed in the learning activities will become more active and positive. First, students will be more active into learning activities. Specific teaching, the student is no longer always down and listened to teachers explain while taking notes, no longer always limitations answer textbook. The students in this teaching structure need to do is go into the learning environment, usually in small groups, the use of resources in real life (usually provided by a computer network-based) to try to solve the problem or complete the task. This learning process is emphasized that the application of knowledge to practice through cooperation with peers as well as actively engaged in discussion, so that the knowledge to get the full and effective deepening. Second, students take on the role of the researcher. Inquiry learning using computers and curriculum integration requires students to go into the study to the researcher's role. Need to learn the structure of this teaching to the students, not just information, it is more important to the scene to investigate and research needs of students with problems and tasks. Meaningful knowledge construction in the process of investigation and research, the students learned related knowledge, including the structure of language, cultural background, the communicative function, and application ability. Third, students need to become skilled operator of a computer technology. Skilled technical operations: (a) skilled application of foreign language learning technology tools, such as word processing, spreadsheet, database, Web browser, e-mail and multimedia presentations; (b)understand and are familiar with the application functions of the computer, which means understanding and familiar with the circumstances in which what the appropriate technical capabilities. When the students 'abilities and computer functions match, the computer can achieve the effect of extending students' ability. So that students have more time and energy to discover and create new knowledge meaningful learning and Construction. Therefore, only the formation of a student-centered teaching structure, the computer network in order to truly become the essential integral part of the students' learning process.

\section{CONCLUSIONS AND OUTLOOK}

Through the above analysis and discussion, we should be on the computer and foreign language teaching relationship with understanding and awareness of the more profound and clear: First, the computer can be very effective to improve the effectiveness and efficiency of the teaching and learning; Second, in highly developed computer technology requirement too low today, just the computer as an auxiliary tool to improve teaching efficiency too, does not meet the needs of the times and the current requirements of the college English teaching reform; third, we should really computer efficiently applied to foreign language teaching, it give full play to the powerful features, the computer must be integrated with the curriculum, making it an organic part of the curriculum, so as to more effectively implement the "computer-and classroom-based English teaching mode.

This paper is sponsored by the Hunan Province General Colleges and Universities Teaching Reform Project (No. 2012-401-482).

\section{REFERENCES}

[1] Bax, S. (2000) Putting technology in its place. In: Field, C. (Ed.), Issues in Modern Foreign Languages Teaching. Routledge, pp. 208219.

[2] Bax, S. (2003) CALL - past, present and future. System 31,13-28.

[3] Brooks, J. G. \& Brooks, M. G. (1993) In Search of understanding: The Case for Constructivist Classroom. Alexandria, VA: Association for Supervision and Curriculum Development.

[4] Brown, J. S., Collins, A. \& Duguid, P. (1989) Situated Cognition and the Culture of Learning. Education Researcher, 18, 32-42

[5] Brunner, J. S. (1960) The Precess of Education. Cambridge, MA: Harvard University Press.

[6] Chambers, A. \& Bax, S. (2006) Making CALL work: Towards normalization. System 34, 465- 479.

[7] Gardner, H. (1991) The Unschooled Mind: How Children Think and How Schools Should Teach. New York: Basic Books.

[8] Greeno, J., Collins, A. \& Resnick, L. (1996) Cognition and Learning. In R. Calfee \& D. Berliner (eds.), Handbook of Educational Psychology. New York: Macmillan.

[9] Jonassen, D. J. (1996) Handbook of Research for Educational Communication and Technology. New Jersey: Prentice Hall.

[10] Levy, M. and Stockwell, G. (2006) CALL Dimensions: Options and Issues in Computer-Assisted language Learning. Lawrence Erlbaum Associates, Inc.

[11] Morrison, G. R \& Lowther, D. L (2005) Integrating Computer Technology into Classroom. Pearson Education, Inc.

[12] Vygotsky, L. (1978) Mind in Society. Cambridge, MA: Harvard University Press. 